\title{
Cutaneous Xanthoma- A Clue to Familial Hypercholesterolemia
}

\author{
Shilpa Accamma Philip ${ }^{1}$, Swarna Sri², Anunayi Jeshtadi ${ }^{3}$
}

\begin{abstract}
${ }^{1}$ Department of Pathology, Osmania Medical College, Koti, Hyderabad, Telangana, India. ${ }^{2}$ Department of Pathology, Osmania Medical College, Koti, Hyderabad, Telangana, India.

${ }^{3}$ Department of Pathology, Osmania Medical College, Koti, Hyderabad, Telangana, India.
\end{abstract}

\section{PRESENTATION OF CASE}

A thirty-year-old female presented with multiple non-tender symmetrical slow growing swellings over dorsal aspect of bilateral foot, bilateral elbows and over interphalangeal joints for 5 years. The patient had similar swellings over the natal cleft, left knee, and dorsum of the hand which was surgically excised fifteen years ago. Her elder brother and sister also had similar complaints of multiple painless swellings.

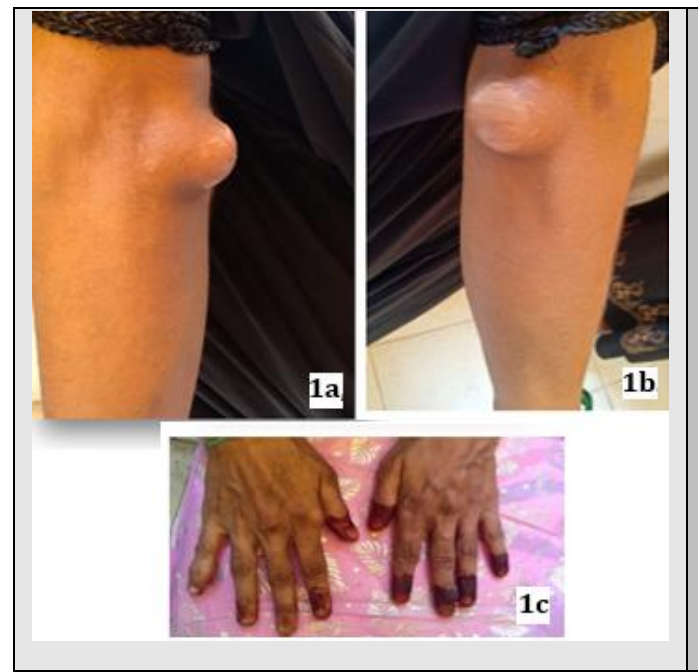

Figure 1a, $1 b$.

Swellings Over Bilateral Elbows, 1c. Multiple Swellings Noted at Distal Interphalangeal Joints in Both Hands and Metacarpophalangeal Joint in Right Hand
Corresponding Author: Dr. Shilpa Accamma Philip, Madapattil House,

Kuttapuzha P. O., Tiruvalla-689103, Kerala, India.

E-mail: shilparulz9317@gmail.com

DOI: $10.14260 /$ jemds/2020/410

Financial or Other Competing Interests: None.

How to Cite This Article:

Philip SA, Sri S, Jeshtadi A. Cutaneous xanthoma- a clue to familial hypercholesterolemia. J. Evolution Med. Dent. Sci. 2020;9(25):1887-1889, DOI: $10.14260 /$ jemds $/ 2020 / 410$

Submission 20-08-2019,

Peer Review 24-05-2020,

Acceptance 01-06-2020,

Published 22-06-2020.

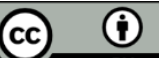

On examination these swellings were multiple, non-tender, soft to firm in consistency and mobile with normal skin overlying the swelling. 

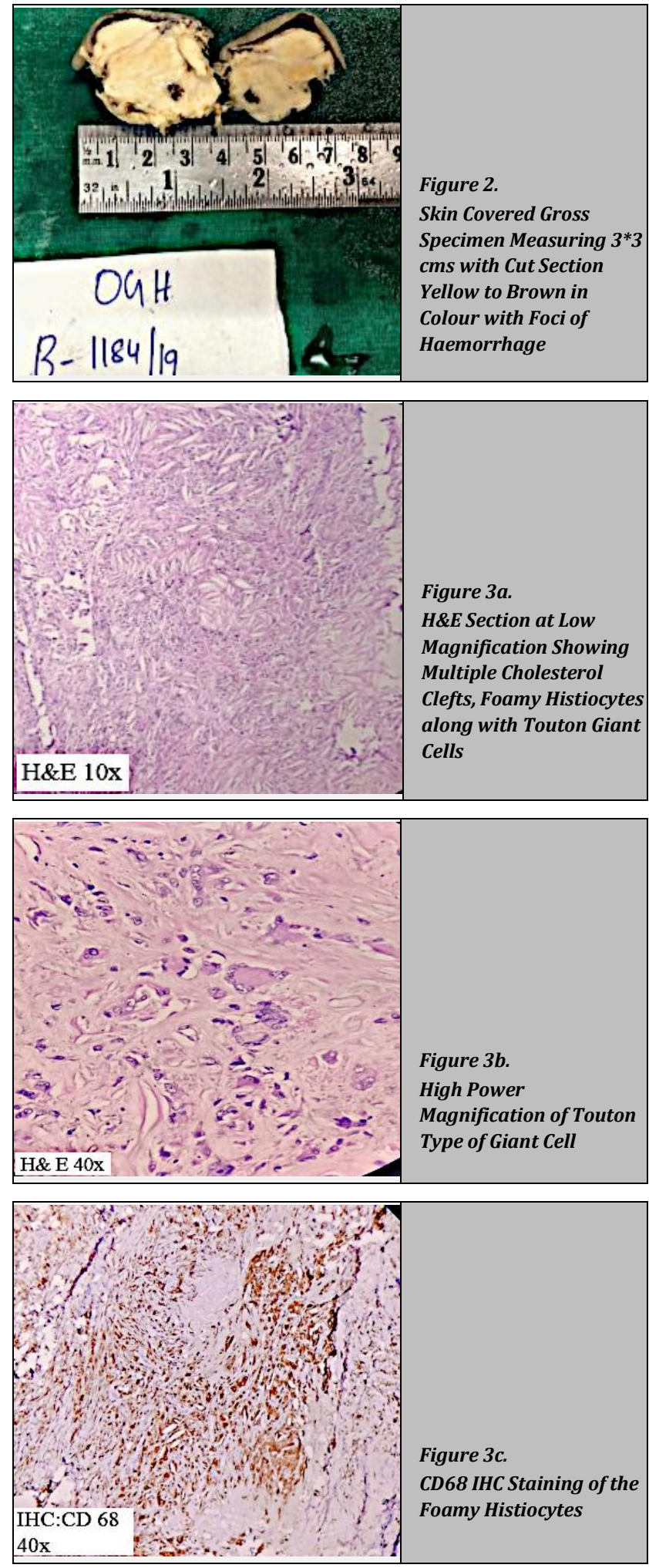

CLINICAL DIAGNOSIS

Xanthoma

\section{DIFFERENTIAL DIAGNOSIS}

Multiple Lipomatosis.

\section{PATHOLOGICAL DISCUSSION}

Her Lipid profile revealed a Total Cholesterol: $541 \mathrm{mg} / \mathrm{dl}$ (<200: desirable) or $30.0 \mathrm{mmol} / \mathrm{L}$, Triglycerides $96 \mathrm{mg} / \mathrm{dl}$ or $5.32 \mathrm{mmol} / \mathrm{L}$ (<150: Normal), LDL levels: $477 \mathrm{mg} / \mathrm{dl}$ or 26.4 $\mathrm{mmol} / \mathrm{L}$ (<100: optimal), HDL levels: 28 or $1.554 \mathrm{mmol} / \mathrm{L}$ (40: Low), Cholesterol/HDL ratio: 19.3 ( $>11.0$ : High Risk), HDL/LDL Ratio: 17.0 (>6 High Risk), VLDL: 19.2 (<30: Normal).

\section{Histopathology Report}

Grossly a skin covered swelling measuring $3 * 3 \mathrm{~cm}$ with cut surface showing a variegated colour ranging from yellow to brown to white with a focus of haemorrhage. Histopathological examination revealed them to be xanthomas characterized by foamy histiocytes, cholesterol clefts and multinucleated touton type of giant cells.

Immunohistochemical marker CD68 was used to confirm diagnosis which is demonstrated by the foamy macrophages.

The present report was consistent with the histopathological reports of previously excised swellings which also revealed to be Xanthoma.

Xanthomas are non-neoplastic lesions which are characterized by yellow macules or papules, to subcutaneous plaques and nodules localized to tendons (tendinous nodules) because of deposition of lipid laden macrophages in dermis and subcutis. ${ }^{[1]}$ It is not a true tumour. It is a reactive histiocytic proliferation that occurs as a response to alterations in serum lipids.[2] Pathogenesis of xanthomas is similar to the pathogenesis in early stages of atherosclerotic plaques and this has brought interest and significance in patients presenting with xanthomas. ${ }^{[3]}$

In 1835 Rayer introduced cutaneous xanthomas for first time. In 1908, it was found that xanthomas may be seen with an increase in serum cholesterol by Pick \& Pinkus. Later in 1938, Thannhauser \& Magendantz put forward the first biochemical classification of the dyslipidosis based on serum lipids. They classified it into three groups namely: Hypercholesterolaemia, Hyperlipidemias (Hypertriglyceridaemia) and Normolipemia. Then Frederickson, Lees \& Levy (1967) proposed a classification of familial hyperlipidaemia based on the electrophoretic patterns of plasma lipoproteins.[4]

Familial hypercholesterolemia (FH), is a primary inherited hyperlipoproteinemia. It is an autosomal codominant genetic disorder caused by mutations in the LDL receptor gene located on chromosome 19. Familial hypercholesterolemia (FH) shows association with increased risk of premature cardiovascular disease. There are two types of FH: A Homozygous $\mathrm{FH}(\mathrm{HoFH})$, have two mutant LDL receptor alleles, and when there is one mutant allele is known as Heterozygous $\mathrm{FH}$ (HeFH). Homozygous familial hyperlipidemia is affected more severely than the latter.[5,6]

The prevalence of molecularly defined HoFH is one in 300,000 individuals and the prevalence of heterozygous $\mathrm{FH}$ is one in 250 individuals,[7] The commonly followed diagnostic criteria for FH is the Dutch Lipid Clinic Network criteria. These criteria calculate a score based on LDL-C levels, the presence 
of arcus cornealis and tendon xanthomas, hypercholesterolaemia and premature CVD in relatives, and positive genetic testing. This is used only for the identification of Index Cases and a total score $>8$ gives a definitive diagnosis.[8]

On applying the above criteria to our patient 1) Family history of first degree relative has presented with xanthoma (score of 2), 2) Presence of tendon xanthomas on bilateral elbows (score of 6), 3) LDL cholesterol levels being more than $8.5 \mathrm{mmol} / \mathrm{L}$ (score of 8) giving an aggregate score more than 8 thereby making a clinically definite diagnosis of Heterozygous Familial Hypercholesterolemia.

Xanthomas are of various types including xanthelasma palpebrum, tuberous xanthomas, tendinous xanthomas, eruptive xanthomas, plane xanthomas, xanthoma disseminatum and giant gluteal xanthoma. Among the various types of xanthomas tuberous and tendinous xanthomas are characteristic of familial hypercholesterolemia and that too mainly in homozygous FH. [9]

Cutaneous xanthomas in cases of FH increases the risk of coronary artery disease as much as threefold.[10] Xanthomas may be the only clinical presentation of the underlying grave lipid abnormality. Therefore Xanthomas pose a much larger threat than a simple cosmetic lesions..[11] They remain gravely underdiagnosed and delayed diagnosis can lead to further consequences as it can progress rapidly to atherosclerotic changes leading to Aortic Stenosis and Coronary Artery Disease.

\section{DISCUSSION OF MANAGEMENT}

Lifestyle and non-cholesterol risk factor modification is an important part of treatment. These include dietary modification, physical exercise, avoidance of weight gain, cessation of smoking.[12] Various studies tell us that statins markedly reduce the risk of coronary artery disease and total mortality in FH.[13]

International guidelines outline $\mathrm{LDL}-\mathrm{C}<2.6 \mathrm{mmol} / \mathrm{L}$ as the optimal target in adults with FH. All statins have been used in FH but adult patients require high-intensity statin therapy, like Atorvastatin $40-80 \mathrm{mg}$ or Rosuvastatin $20-40 \mathrm{mg}$. Women with FH should receive pre-pregnancy counselling as they should be advised to stop any lipid-lowering treatment at least 4 weeks before discontinuing contraception and should not use statins in pregnancy and lactation. Ezetimibe and bile acid sequestrants are other options.[14] For patients failing to attain target LDL-C, the new PCSK9 inhibitors helps in reducing LDL$\mathrm{C}$ and thereby cardiovascular risk. In cases of severe $\mathrm{HoFH}$, lomitapide and LDL apheresis are indicated.[15]

Our patient is currently advised Atorvastatin $40 \mathrm{mg}$ along with regular cardiovascular follow up.

\section{FINAL DIAGNOSIS}

Thirty-year-old lady with familial heterozygous hypercholesterolemia with multiple, recurrent cutaneous and tendon xanthomas.

\section{REFERENCES}

[1] Kumar S, Gupta P, Bhardwaj M, et al. Cutaneous xanthomas in a young child: familial hypercholesterolemia. Indian Dermatol Online J 2017;8(5):375-6.

[2] Goldblum J, Weiss S, Folpe AL Benign fibrohistiocytic and histiocytic tumors. In: Enzinger \& Weiss s soft tissue tumors. Elsevier 2019:471-4.

[3] Zak A, Zeman M, Slaby A, et al. Xanthomas: clinical and pathophysiological relations. Biomed Pap Med Fac Univ Palacky Olomouc Czech Repub 2014;158(2):181-8.

[4] Fleischmajer R, Schragger AH. The clinical significance of cutaneous xanthomas. Postgrad Med J 1970;46(541):6717.

[5] Palacio CH, Harring TR, Nguyen NTT, et al. Homozygous familial hypercholesterolemia: case series and review of the literature. Case Rep Transplant 2011;2011:1-5.

[6] Bouhairie VE, Goldberg AC. Familial hypercholesterolemia. Cardiol Clin 2015;33(2):169-79.

[7] Alonso R, de Isla LP, Muñiz-Grijalvo O, et al. Familial hypercholesterolaemia diagnosis and management. ECR Cardiol 2018;13(1):14-20.

[8] World Health Organization. Familial hypercholesterolemia: report of a second WHO consultation. Geneva: World Health Organization 1999:13-4.

[9] Dwivedi S, Jhamb R. Cutaneous markers of coronary artery disease. World J Cardiol 2010;2(9):262-9.

[10] Mabuchi H. Half a century tales of familial hypercholesterolemia (FH) in Japan. J Atheroscler thromb 2017;24(3):189-207.

[11] Mastrolorenzo A, D’Errico A, Pierotti P, et al. Pleomorphic cutaneous xanthomas disclosing homozygous familial hypercholesterolemia. World J Dermatol 2017;6(4):5965.

[12] Watts GF, Gidding S, Wierzbicki AS, et al. Integrated guidance on the care of familial hypercholesterolemia from the International FH Foundation. J Clin Lipidol 2014;8(2):148-72.

[13] Mortality in treated heterozygous familial hypercholesterolaemia: implications for clinical management. Scientific Steering Committee on behalf of the Simon Broome Register Group. Atherosclerosis 1999;142(1):105-12.

[14] Nordestgaard BG, Chapman MJ, Humphries SE, et al. Familial hypercholesterolaemia is underdiagnosed and undertreated in the general population: guidance for clinicians to prevent coronary heart disease: consensus statement of the European Atherosclerosis Society. Eur Heart J 2013;34(45):3478-90a.

[15] Rader DJ, Kastelein JJP. Lomitapide and mipomersen: two first-in-class drugs for reducing low-density lipoprotein cholesterol in patients with homozygous familial hypercholesterolemia. Circulation 2014;129(9):1022-32. 